đưa ra những hướng dẫn với bác sĩ điều tri, điều dưỡng và người nhà chăm sóc bệnh nhân để nâng cao hiệu quả điều trị bệnh nhân trầm cảm nặng có ý tưởng hành vi tự sát.

\section{TÀI LIẸU THAM KHẢO}

1. Tổ chức y tế thế giới (2020) Preventing suicide: A global imperative.

2. Bachmann S. (2018). Epidemiology of Suicide and the Psychiatric Perspective. Int J Environ Res Public Health, 15(7).

3. Sức khóe tâm thân ở Việt Nam. $<$ https://www.who.int/vietnam/vi/healthtopics/mental-health>, accessed: 18/10/2020.

4.Tố chức y tế thế giới (1992). "Phân loại bệnh quốc tế lân thứ 10 về các rối loạn tâm thần và hành vi".

5. Bùi Quang Huy, Cao Tiến Đức (2004). Nghiên cứu một số đặc điểm dịch tễ và lâm sàng ở BN tâm thần có hành vi tự sát. Tạp chí Y - Dược học quân sự. 2004, số 2, tr.92-96.

6. Van Gastel A, Schotte $C_{\text {, Maes }} \mathbf{M}$. The prediction of suicidal intent in depressed patients. Acta Psychiatr Scand. 1997, Oct, 96 (4), pp.254-259.

7. Bưi Quang Huy (2013) Nghiên cứu về hành vi tự sát trên bệnh nhân rối loạn trầm cảm nặng. Tạp chí y học quân đội số 4, 2013.

8. Nguyến Hữu Kỳ (1996). Nghiên cứu sự liên quan giữa yếu tố ngoại lai, nhân tố tâm lý và nhân tố bệnh tâm thân ở những người toan tự sát. Luận án Tiến sỹ $Y$ học. Trường Đai hoc $Y$ Hà Nôi.

9. Dương Duy Đăng (2010) Đánh giá ý tưởng và hành vi tự sát trên người bệnh rối loạn trầm cảm năng. Luẩn văn chuyến khoa cấp 2 - Trường Đại học Y Hà Nội.

\title{
TỔNG QUAN VỀ KẾT QUẢ PHẪU THUÂTT CẮT THÙYY TUYẾN GIÁP TRONG VI UNG THƯ TUYẾN GIÁP THỂ NHÚ
}

\section{TÓM TẮT}

Mục tiêu: Tổng quan này nhằm để đánh giá kết quả sau phẫu thuâat cắt thùy giáp (tỷ lệ tử vong, tỷ lệ sống toàn bộ và tỷ lệ tái phát) và đưa ra các điều kiện để chỉ định phẫu thuất cắt thùy giáp ở bênh nhân vi ung thư tuyến giáp (UTTT) thể nhú. Phương pháp: Chúng tôi sử dung cơ sở dữ liêu PUBMED và EMBASE để đánh giá kết quả và điêu kiện chỉ định của phương pháp phẩu thuật cắt thùy giáp cho vi UTTG thể nhú. Kết quả: Có 09 nghiên cứu gồm 5345 bệnh nhân trong tổng quan này, thời gian theo dõi trung bình $64,6-134,8$ tháng. Trong các nghiên cứu này, chúng tôi không thây trường hợp tử vong nào liên quan đến UTTG sau phầu thuật cắt thùy giáp. Tỷ lệ sống không bênh theo phương pháp Kaplein-Meier của nhóm cắt thùy thấp hơn ở nhóm cắt toàn bộ tuyến giáp. Tỷ lệ tái phát tổng thể sau phẫu thuật cắt thùy giáp là 2,5 $\%$, vị trí tái sau phẫu thuật này tại thùy giáp còn lại là $75,3 \%$, tai giường tuyến giáp là $1,5 \%$ và di căn hach cố là $23,2 \%$. Không có trường hợp di căn xa trong thời gian theo dõi. Kết luận: Cắt thùy giáp có kết quả tương tự như cắt toàn bộ tuyến giáp trong vi UTTG thể nhút tỷ lệ tử vong, thời gian sống toàn bộ, tỷ lệ tái phát). Do vậy có thể chỉ định cắt thùy giáp cho vi UTTG thể nhú với các điều kiện được thỏa mãn.

\section{SUMMARY}

\footnotetext{
${ }^{1}$ Bệnh viện đại học Y Hà Nội.

${ }^{2}$ Trường đại học Y Hà Nội.

Chịu trách nhiệm chính: Trần Thế Diệu

Email: tranthedieu2009@gmail.com

Ngày nhận bài: 25.10.2021

Ngày phản biên khoa họ: 20.12.2021

Ngày duyệt bài: 30.12.2021
}

\section{SCOPING REVIEW OF THE OUTCOMES OF THYROID LOBECTOMY IN PAPILLARY THYROID MICROCARCINOMA}

Objective: This review evaluates the outcomes after lobectomy (mortality rate, overall survival rate, and recurrence rates) and give the standards of the indication for lobectomy in patients with papillary thyroid microcarcinoma. Methods: We used the PUBMED and EMBASE databases to evaluate the results and indications of lobectomy for papillary thyroid carcinoma. Results: There were 09 studies with 5345 patients in this overview, the average follow-up time was 64.6 - 134.8 months. In these studies, we did not see any deaths related to thyroid carcinoma after lobectomy. Kaplein-Meier disease-free survival was lower in lobectomy group than total thyroidectomy group. The overall recurrence rate after lobectomy is $2.5 \%$, the recurrence site after this surgery is $75.3 \%$ in the remaining thyroid lobe, $1.5 \%$ at the thyroid bed, and cervical lymph node metastasis is $23.2 \%$. There were no cases of distant metastases during the follow-up period. Conclusion: Lobectomy has similar results as total thyroidectomy in papillary thyroid carcinoma (mortality rate, overall survival, recurrence rate). Therefore, lobectomy may be indicated for papillary thyroid microcarcinoma, provided the standards conditions are satisfied.

\section{I. ĐẶT VẤN ĐỀ}

Vi UTTG thể nhú theo định nghĩa của Tổ chức $Y$ tế Thế giới (WHO), là các ung thư tuyến giáp thể nhú có đường kính tối đa $1 \mathrm{~cm}$. Tỷ lệ mắc vi ung thư biểu mô tuyến giáp thể nhú ngày càng tăng lên, năm 2014 hơn 50\% các trường hợp UTTG mắc mới là vi UTTG thể nhúi1-3. Tuy nhiên, 
tỷ lệ tử vong liên quan đến vi UTTG thể nhú không tăng lên đáng kể.

Hiện nay phẫu thuâtt là phương pháp chính để điều trị vi UTTG thể nhú. Tuy nhiên vẫn có những tranh cãi về mức độ phẫu thuật vi UTTGthể nhú. Một số bác sĩ lâmm sàng cho rằng dù tiên lượng tốt, nhưng vi UTTG thể nhú có khả năng tái phát và di căn ${ }^{4-7}$. Nên phẫu thuật cắt toàn bộ tuyến giáp được ủng hộ. Ngược lại, một số bác sĩ thấy rằng bệnh nhân vi UTTG thể nhú phải phẫu thuật cắt toàn bộ tuyến giáp là quá mức và không có cơ sở, như thiếu bằng chứng đầy đủ để chứng minh phương pháp này có thể làm giảm nguy cơ tái phát và tử vong ${ }^{8}$. Các hướng dẫn gần đây của Hiệp hội tuyến giáp Hoa Kỳ cho rằng chỉ cắt bỏ thùy tuyến giáp có thể đủ để điều trị vi UTTG thể nhú ${ }^{\text {? }}$.

ở Việt Nam và trên thế giới chưa có nhiều nghiên cứu tổng quan về kết quả sau phẫu thuật cắt thùy giáp ở bệnh nhân vi UTTG thể nhú. Chúng tôi thực hiện tổng quan này, nhằm đánh giá kết quả lậm sàng ở bệnh nhân vi UTTG thể nhú được phẫu thuật cắt thùy tuyến giáp và tìm hiểu các điều kiện để chỉ định cắt thùy giáp đối với vi UTTG thể nhú của các tác giả trên thế giới.

\section{II. Đốl TƯợNG VÀ PHƯƠNG PHÁP NGHIÊN CứU}

1. Công cư nghiên cứu: Nghiên cứu tổng quan này dựa trên protocols PRISMA-P 2009.

2. Nguồn cơ sở dữ liệu và chiến lược tìm kiếm tài liệu. Chúng tôi tìm kiếm một cách hệ thống vào ngày 2 tháng 5 năm 2021 trên các cớ sở dữ liệu PubMed, EmBase và sử dụng từ khóa để tìm kiếm qua công cụ MESH là: "Thyroidectomy" AND "Papillary Thyroid microcarcinoma".

3. Quá trình lựa chọn các nghiên cứu. Tất cả các bài báo nghiên cứu gốc về kết quả phẫu thuật cắt thùy giáp trong vi UTTG thể nhú đều được xem xét. Tên nghiên cứu, tóm tắt nghiên cứu, toàn văn lần lượt của các bài báo được đánh giá bởi ba nhà nghiên cứu độc lập là Nguyễn Quang Trung, Nguyển Văn Hùng và Trần Thế Diệu. Chi tiết quá trình lựa chọn trình bày chi tiết ở hình 1.

\section{KẾT QUẢ NGHIÊN CỨU}

1. Đắc điểm các bài báo được lựa chọn. Có tất cả 9 bài báo được chọn vào trong nghiên cứu tổng quan này (đều bằng tiếng Anh), được công bố từ năm 2015 đến năm 2019, với tổng số bệnh nhân vi UTTG thể nhú được phẫu thuật cắt thùy tuyến giáp là 5345 .

6 nghiên cứu so sánh kết quả giữa cắt TBTG và cắt thùy giáp, 3 nghiên cứu theo dõi kết quả lâu dài sau cắt thùy giáp ở những bệnh nhân vi UTTG thể nhú. Với thời gian theo dõi trung bình từ $64,6-134,8$ tháng.

2. Tỷ lệ sống toàn bộ, tỷ lệ tử vong sau phẫu thuật cắt thùy tuyến giáp. Chúng tôi thây rằng không có sự khác biệt ở nhóm cắt thùy giáp và cắt toàn bộ tuyến giáp cho vi UTTG thể nhú trong ba nghiên cứu kiểm tra tỷ lệ sống toàn bộ, tỷ lệ tử vong. Nghiên cứu của Donatini không quan sát thấy bệnh nhân tử vong trong thời gian theo dõi trung bình 11,2 năm ở nhóm cắt thùy giáp.

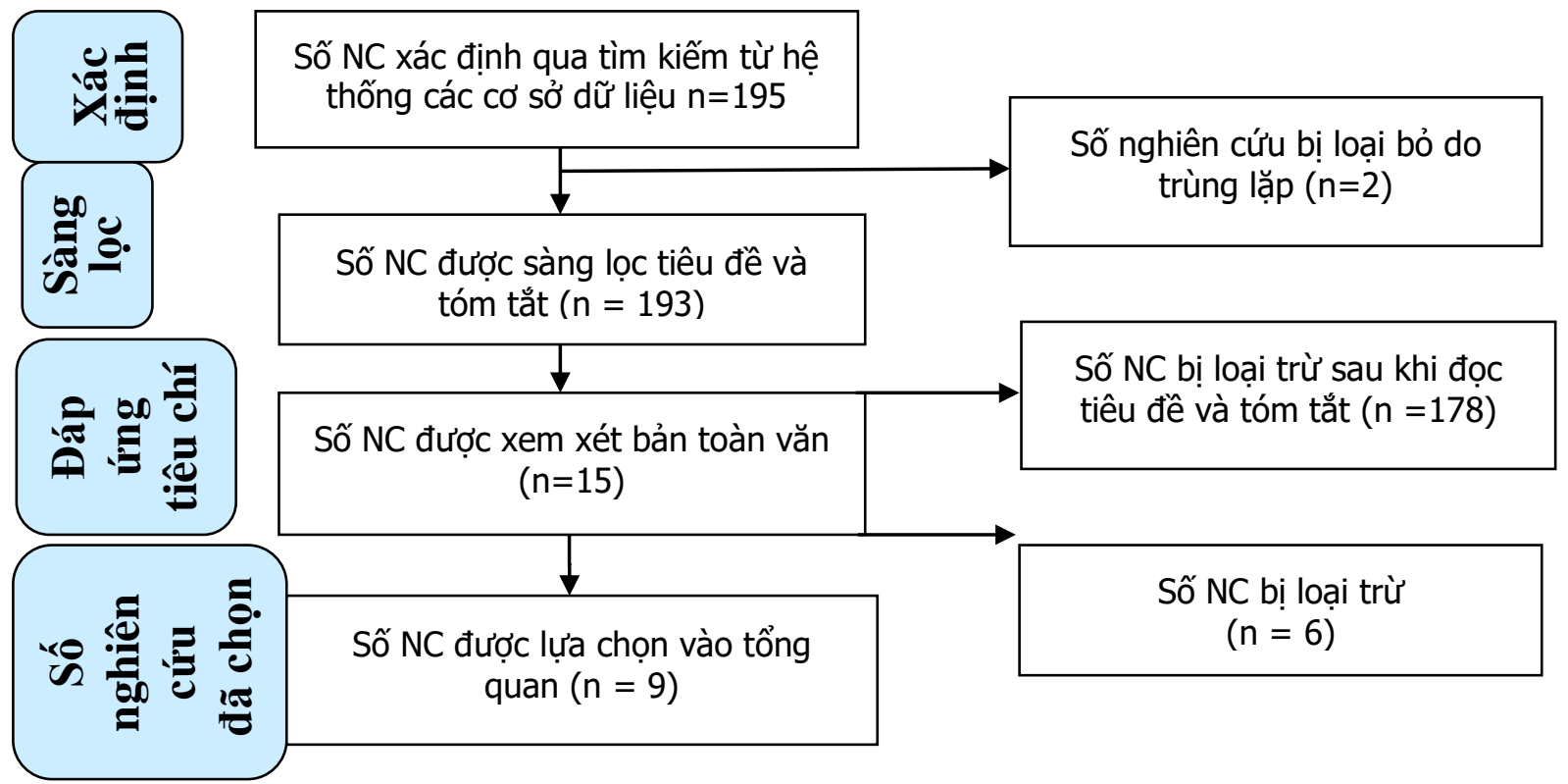

Hình 1. Sơ đồ chi tiêt quá trình lựa chọn và loại trừ các bài báo vào nghiên cứu. 
Với nghiên cứu còn lại của Dobrinja có quan sát thây bệnh nhân tử vong nhưng đều xác định là tử vong không liên quan đến UTTG thể nhú. Xue và cộng sự mô tả đường cong tỷ lệ sống toàn bộ cửa bệnh nhân vi UTTG sau phẫu thuật thấy không có sự khác biệt có ý nghĩa thống kê giữa nhóm phẫu thuật cắt thùy giáp so với nhóm cắt toàn bộ tuyến giáp.

Bảng 1. Các nghiên cứu về cắt thùy và cắt toàn bộ tuyến giáp

\begin{tabular}{|c|c|c|c|c|c|c|c|c|c|c|c|}
\hline $\begin{array}{l}\text { Nghiên } \\
\text { cứu }\end{array}$ & $\begin{array}{l}\text { Thời } \\
\text { gian } \\
\text { NC }\end{array}$ & $\begin{array}{l}\text { Số } \\
\text { BN }\end{array}$ & Tuổi & Giới & $\begin{array}{l}\mathrm{KT} \mathrm{U} \\
(\mathrm{mm})\end{array}$ & \begin{tabular}{|l} 
U phá \\
vớ vỏ
\end{tabular} & $\begin{array}{c}\text { Đa } \\
\text { nhân }\end{array}$ & $\begin{array}{c}\text { Di căn } \\
\text { hạch }\end{array}$ & $\begin{array}{c}\text { Tỷ lệ } \\
\text { tái } \\
\text { phát }\end{array}$ & $\begin{array}{c}\text { Tỷ lệ } \\
\text { tữ } \\
\text { vong }\end{array}$ & $\begin{array}{c}\text { Thời gian } \\
\text { theo dôi }\end{array}$ \\
\hline $\begin{array}{l}\text { Donatini } \\
\text { et al (2015) }\end{array}$ & 24 năm & 69 & NA & NA & 7,1 & NA & $7,3 \%$ & NA & $17,4 \%$ & 0 & 134,8tháng \\
\hline $\begin{array}{c}\text { Dobrinja } \\
\text { et al (2017) }\end{array}$ & 15 năm & 19 & 56 & $4 / 15$ & 5,3 & $10,5 \%$ & $5,3 \%$ & 0 & $5,3 \%$ & 0* & 58,5tháng \\
\hline $\begin{array}{c}\text { Kim et al } \\
(2016)\end{array}$ & 18 năm & 3289 & $\begin{array}{c}45,5+/ \\
-10,5 \\
\end{array}$ & $\begin{array}{l}711 / \\
2578 \\
\end{array}$ & \begin{tabular}{|c|}
$0,5+$ \\
$-0,2$ \\
\end{tabular} & $31,4 \%$ & $11,7 \%$ & $13,8 \%$ & $1,6 \%$ & NA & 64,6tháng \\
\hline $\begin{array}{c}\text { Jeon et al } \\
(2019)\end{array}$ & 13 năm & 127 & $\begin{array}{r}47,65+ \\
-10,39 \\
\end{array}$ & $16 / 111$ & \begin{tabular}{|c|}
$6,34+-$ \\
2,20 \\
\end{tabular} & $12,6 \%$ & $100 \%$ & NA & $3,15 \%$ & NA & 94,8tháng \\
\hline $\begin{array}{c}\text { Kwon et } \\
\text { Al (2017) }\end{array}$ & 9năm & 668 & 47 & $60 / 628$ & 6 & $38 \%$ & $10 \%$ & $26 \%$ & $3,8 \%$ & NA & 8,5năm \\
\hline $\begin{array}{c}\text { Xue et al } \\
(2017)\end{array}$ & 1năm & 57 & $49+-10$ & $12 / 45$ & NA & $10,53 \%$ & NA & $9,65 \%$ & $26 \%$ & $3,5 \%$ & NA \\
\hline $\begin{array}{c}\text { Choi et al } \\
(2019)\end{array}$ & 1năm & 179 & $\begin{array}{c}45,3+ \\
-9,5\end{array}$ & $158-21$ & $\begin{array}{c}6,6+- \\
1,9 \\
\end{array}$ & 0 & $34 \%$ & NA & $2,8 \%$ & NA & $\begin{array}{c}80.7 \pm \\
\text { 44.8tháng }\end{array}$ \\
\hline $\begin{array}{c}\text { Baek et al } \\
(2017)\end{array}$ & 1năm & 800 & $\begin{array}{c}43,9+- \\
10,1 \\
\end{array}$ & |586-214 & \begin{tabular}{|c|}
$5,2+-$ \\
1,9 \\
\end{tabular} & NA & NA & $13 \%$ & $2 \%$ & NA & \begin{tabular}{|c|}
$77,3+$ \\
$-18,6$ tháng \\
\end{tabular} \\
\hline $\begin{array}{c}\text { Kim et al } \\
(2016)\end{array}$ & 1năm & 137 & NA & NA & \begin{tabular}{|c|}
$6.4 \pm$ \\
1.9 \\
\end{tabular} & NA & NA & $14,6 \%$ & $1,5 \%$ & NA & $\begin{array}{c}61.3 \pm \\
29.9 \text { tháng } \\
\end{array}$ \\
\hline & & 5345 & & & & $30,6 \%$ & $13,9 \%$ & $15,8 \%$ & $2,5 \%$ & & \\
\hline
\end{tabular}

3. Tình trạng tái phát và tỷ lệ sống không bệnh sau phẫu thuật cắt thùy giáp.

3.1. Tỷ lệ tái phát tổng thể. Tỷ lế tái phát tổng thể sau phẫu thuật cắt thùy giáp cho vi UTTG thể nhú là: 2,5\% (131/5345). Tỷ lệ tái phát của các nghiên cứu được trình bày chi tiết trong bảng 1 .

3.2. Tái phát tại chỗ (Giường tuyến giáp, thùy giáp còn lại). Sau khi tính toán và phân tích chúng tôi thấy sau phẫu thuật cắt thùy giáp chỉ có $1,5 \%$ tái phát ở vị trí giường tuyến giáp $(2 / 137)$, phần lớn tái phát ở thùy còn lại chiếm 75,2\% trường hợp (103/137). Các số liệu chi tiết được trình bày trong bảng 2 .

3.3. Di căn hạch cổ. Số trường hợp tái phát tại hạch cổ chiếm 23,3\% (32/137). Có 6 trường hợp tái phát ở 2 vị trí là thùy giáp còn lại và hạch bạch huyết vùng cổ.

3.4. Di căn xa: trong các nghiên cứu đưa vào tổng quan này, chúng tôi không thấy trường hợp di căn xa nào sau phẫu thuật được ghi nhận.

3.5. Tỷ lệ sống không bệnh sau phẫu thuật cắt thùy tuyến giáp. Chúng tôi thấy có 5/9 nghiên cứu so sánh sự khác biệt tỷ lệ sống không bệnh đều được phân tích theo phương pháp Kaplein-Meier. Chỉ có nghiên cứu của Jeon và cộng sự cho thấy tỷ lệ sống không bệnh giữa
2 nhóm không khác biệt có ý nghĩa thống kê có giá trị $\mathrm{P}=0,224$ (số bệnh nhân 255). Còn 4 nghiên cứu còn lại cho kết quả có sự khác biệt có ý nghĩa thống kê về tỷ lệ sống không bệnh giữa 2 nhóm, nhóm cắt toàn bộ tuyến giáp có tỷ lệ cao hơn nhóm cắt thùy giáp (các giá trị $\mathrm{P}<0,05$ được trình bày chi tiết ở bảng 3 ). Tuy nhiên nghiển cứu của Kwon và cộng sự (2017), là 1 nghiên cứu có chất lượng cao chia 2 nhóm phẫu thuật cắt thùy giáp và cắt toàn bộ tuyến giáp (mỗi nhóm có 688 bệnh nhân). Các tác giả thấy rằng tỷ lệ sống khổng bệnh ở nhóm cắt thùy giáp sau khi được cắt thùy giáp tái phát so với nhóm cắt toàn bộ tuyến giáp là như nhau với $\mathrm{P}=0,08(>0,05)$.

\section{Các điêu kiện lựa chọn phẫu thuâat cắt} thùy tuyến giáp trong vi UTTG thể nhú.

Tất cả các tác giả đều đồng thuận điều kiện cần thiết để phẫu thuật cắt thùy là ung thư tuyến giáp thể nhú với đường kính lớn nhất của nhân ung thư' $<=1 \mathrm{~cm}$ (9/9 nghiên cứu).

Ngoài ra chúng tôi thấy rằng những điều kiện khác phần lớn các tác giả lựa chọn để chỉ định phẫu thuật cắt thùy giáp cho vi UTTG thể nhúlà: đơn nhân (4/9 nghiên cứu); tổn thương nằm hoàn toàn trong tuyến giáp, không phá võ vỏ trên đại thể, không xâm lấn các cấu trúc xung 
quanh (7/9 nghiên cứu); không có di căn hạch cổ xác định trên siêu âm trước phẫu thuật và phát hiện được trong phẫu thuật $(8 / 9$ nghiên cứu); không có di căn xa (2/9 ghiên cứu); không có tiền sử chiếu xạ vùng cổ ( $3 / 9$ ghiên cứu); không có tiền sử ung thư tuyến giáp có tính chất gia đình (3/9 nghiên cứu). Yếu tố tuổi được đề cập ở 4 nghiên cứu, nhưng chỉ có nghiên cứu của Kim và cộng sự năm 2016 đưa ra mốc tuổi $<45$, tuy nhiên những cập nhật gần đây của AJCC $8^{\text {th }}$ năm 2018 lại đưa mức cut off độ tuổi là $<55$ tuổi, do đó trong cần thêm những nghiên cứu về vấn đề này.

Bảng 2. Vị trí tái phát tại chỗ sau phẫu thuật vi UTTGthể nhú.

\begin{tabular}{|c|c|c|c|c|}
\hline \multirow{2}{*}{ Nghiên cứu } & \multirow{2}{*}{$\begin{array}{c}\text { Tỷ lệ tái } \\
\text { phát }\end{array}$} & \multicolumn{3}{|c|}{ Vị trí tái phát tại chố } \\
\hline & & Thùy đối diện & Giường tuyến giáp & Hạch cố \\
\hline Donatini et al (2015) & $17,4 \%$ & 10 & 1 & 1 \\
\hline Dobrinja et al $(2017)^{2}$ & $5,3 \%$ & 1 & 0 & 0 \\
\hline Kim et al (2016) & $1,6 \%$ & 29 & 1 & 20 \\
\hline Jeon et al $(2019)^{4}$ & $3,15 \%$ & 4 & 0 & $1^{*}$ \\
\hline Kwon et al( 2017$)^{5}$ & $3,8 \%$ & 22 & 0 & 4 \\
\hline Xue et al $(2017)^{6}$ & $26 \%$ & 14 & 0 & 1 \\
\hline Choi et al (2019) ${ }^{7}$ & $2,8 \%$ & 5 & 0 & $1 *$ \\
\hline Baek et al (2017) & $2 \%$ & 16 & 0 & 4* \\
\hline Kim et al $(2016)^{9}$ & $1,5 \%$ & 2 & 0 & 0 \\
\hline & $2,5 \%$ & $103 / 137(75,2 \%)$ & $2 / 137(1,5 \%)$ & $32 / 137(23,3 \%)$ \\
\hline
\end{tabular}

Bảng 3. Tỷ lệ sống không bệnh của các nhóm phâu thuật cắt thùy giáp theo phương pháp Kaplein-Meier

\begin{tabular}{|c|c|c|c|c|}
\hline \multirow{2}{*}{ Nghiên cứu } & \multicolumn{3}{|c|}{ Tỷ lệ sống không bệnh sau phấu thuật cắt } & Giá trị $\mathbf{P}$ \\
& thùy tuyến giáp & \\
\cline { 2 - 5 } & 5 năm & 10 năm & 15 năm & \\
\hline Donatini et al $(2015)^{1}$ & NA & NA & NA & $\mathrm{p}=0,004(<0,05)$ \\
\hline Dobrinja et al $(2017)^{2}$ & $93,7 \%$ & NA & NA & NA \\
\hline Kim et al $(2016)^{3}$ & $98,1 \%$ & $91,8 \%$ & $90,6 \%$ & $\mathrm{p}<0,001$ \\
\hline Jeon et al $(2019)^{4}$ & NA & NA & NA & $\mathrm{p}=0,224(>0,05)$ \\
\hline Kwon et al $(2017)^{5}$ & NA & NA & NA & $\mathrm{P}=0,01(<0,05)$ \\
\hline Xue et al $(2017)^{6}$ & $91,23 \%$ & $73,68 \%$ & NA & $\mathrm{p}=0,0059(<0,05)$ \\
\hline
\end{tabular}

\section{BÀN LUẬN}

Điều trị phẫu thuật ung thư tuyến giáp thể nhú dưới $1 \mathrm{~cm}$ còn là một chủ đề gây tranh cãi và cách tiếp cận tối ưu vẫn chưa được đồng thuận. Nhiều tác giả cho rằng phương pháp cắt thùy tuyến giáp là một phẫu thuật vừa đủ, trong đó có khuyến cáo ATA 2015 (hội tuyến giáp Hoa Kỳ).

Tỷ lệ tử vong và thời gian sống toàn bộ. Trong tổng quan này, nghiên cứu của Donatini, Dobrinja không tìm thấy tỷ lệ tử vong liên quan đến ung thư tuyến giáp thể nhú. Nghiên cứu của Xue và cộng sự đã mô tả đường cong thời gian sống toàn bộ sau phẫu thuật thấy không có sự khác biệt có ý nghĩa thống kê giữa nhóm phẫu thuật cắt thùy giáp so với nhóm cắt toàn bộ tuyến giáp. Các nghiên cứu khác cũng không đề cập tới tỷ lệ tử vong sau phẫu thuật liên quan. Điều này đã xác nhận yếu tố tiên lượng tử vong tổng thể và thời gian sống toàn bô của vi UTTG thể nhú không khác nhau giữa nhóm phẫu thuật cắt thùy giáp so với nhóm cắt toàn bộ tuyến giáp.

1. Tình trạng tái phát. Tỷ lệ tái phát tổng thể của cả 9 nghiên cứu trong tổng quan này là $2,5 \%(131 / 5345)$ với thời gian tái phát trung bình từ 43 tháng - 53 tháng. Thấy tỷ lệ tương đương với nghiên cứu tổng quan hệ thống trước đây của Zheng và cộng sự là 2,56\% ở nhóm cắt toàn bộ tuyến giáp với vi UTTG thể nhú.

Tái phát tại chỗ. Chỉ có 1,5\% trường hợp tái phát ở giường tuyến giáp. Nguyên nhân tái phát tại vị trí này thường do sót nhu mô tuyến giáp sau phẫu thuật vì u xâm lấn ra các mô ở giường tuyến giáp quan trọng (như dây thần kinh thanh quản quặt ngược) mà không thể bóc tách được, hoặc phẫu thuật viên bỏ sót trong quá trình phẫu thuật. Tuy nhiên vi UTTG thể nhú rất ít gặp trường hợp xâm lấn đại thể ra ngoài vỏ tuyến giáp giải thích tại sao tỷ lệ tái phát tại thấp tại giường tuyến giáp.

Vị trí tái phát thường gặp nhất sau phẫu thuật cắt thùy giáp ở những bệnh nhân vi UTTG thể nhú là thùy giáp còn lại $75,2 \%$. Điều này liên quan nhiêu tới tình trạng thùy giáp còn lại tại thời điểm trước phẫu thuật, khi có 20-40\% 
trường hợp vi UTTG là đa nhân. Nghiên cứu của Kim và công sự là 1 nghiên cứu lớn với 8676 bệnh nhân vi UTTG thể nhú cho kết quả trường hợp đa nhân thì phẫu thuật cắt thùy tuyến giáp có nguy cơ tái phát cao hớn so với phấu thuật cắt toàn bộ tuyến giáp có ý nghĩa thống kê.

Tái phát hạch. Di căn hạch cổ chiếm 23,3\% vị trí tái phát sau phẫu thuật cắt thùy giáp. Một tỷ lệ không nhỏ tái phát ở hạch cổ cho thấy rằng tình trạng hach cổ cần được đánh giá kỹ trước và trong mổ để quyết định mức độ phẫu thuật ban đầu cho bệnh nhân để tránh tình trạng tái phát.

Di căn xa. Không có trường hợp di căn xa nào được tìm thấy trong tất cả nghiên cứu trong tổng quan này với 5345 bệnh nhân, mặc dù thời gian theo dõi nghiên cứu đều trên 5 năm và có nghiên cứu lên tới trên 10 năm sau phẫu thuật cắt thùy giáp. Qua điêu này chúng tôi thấy rằng khả năng di căn xa ở nhóm vi UTTG sau phẫu thuật cắt thùy giáp là rất thấp.

Tỷ lệ sống không bệnh. Trong tổng quan này, chúng tôi thấy giá trị liên quan mật thiết đến tình trạng tái phát là tỳ lệ sống không bệnh sau phẫu thuật ban đầu của bệnh nhân sau 5 năm, 10 năm, 15 năm. Hầu hết các nghiên cứu đều cho kết quả tỷ lệ sống không bệnh ở nhóm sau phẫu thuật cắt toàn bộ tuyến giáp cao hơn ở nhóm cắt thùy giáp với $\mathrm{P}<0,05$, có ý nghĩa thống kê. Tuy nhiên nghiên cứu của Kwon và cộng sự đề cập tới khái niệm tỷ lệ sống không bệnh ở những bệnh nhân tái phát thùy còn lại sau phẫu thuật cắt thùy giáp được phẩu thuầt cắt thùy giáp còn lại thấy không có sự khác biệt có ý nghĩa thống kê so với nhóm bệnh nhân cắt toàn bộ tuyến giáp.

2. Các điều kiên lựa chọn phẫu thuât cắt thùy tuyến giáp trong vi UTTG thể nhú. Có nhiều điều kiện để các tác giả chỉ định phương pháp phẫu thuật cho các bệnh nhân vi ung thư tuyến giáp. Tuy nhiên qua quá trình phân tích chúng tôi thấy có 2 nhóm điều kiên chính mà hầu hết tác giả dựa vào lựa chọn phẫu thuật cắt thùy cho bệnh nhẩn vi UTTG thể nhú đó là:

- Nhóm điều kiện cần: (1) ung thư tuyến giáp thể nhú và đường kính lớn nhất của nhân ung thư' $<=1 \mathrm{~cm}$.

- Nhóm điều kiện đủ: (2) Đơn nhân; (3) tổn thương nằm hoàn toàn trong tuyến giáp, không phá vỡ vỏ trên đại thể, không xâm lấn các cấu trúc xung quanh; (4) không có di căn hạch cổ xác định trên siêu âm trước phẫu thuật và phát hiện được trong phẫu thuật; (5) không có di căn xa; (6) không có tiền sử chiếu xa vùng cổ; (7) không có tiền sử ung thư tuyến giáp có tính chất gia đình.

\section{KẾT LUÂN}

Qua nghiên cứu này chúng tôi rút ra kết luận phương pháp cắt thùy giáp có kết quả tương tự như cắt toàn bộ tuyến giáp trong vi UTTG thể nhú (tỷ lệ tử vong, thời gian sống toàn bộ, tỷ lệ tái phát). Do vậy có thể chỉ định cắt thùy giáp cho vi UTTG với các điều kiện thỏa mãn sau: (1) ung thư tuyến giáp thể nhú và đường kính lớn nhất của nhân ung thư' $<=1 \mathrm{~cm}$ (điều kiện cần) và (2) đơn nhân, (3) tổn thương nằm hoàn toàn trong tuyến giáp, không phá vỡ vỏ trên đại thể, không xâm lấn các cấu trúc xung quanh; (4) không có di căn hạch cổ xác định trên siêu âm trước phẫu thuật và phát hiện được trong phẫu thuật; (5) không có di căn xa; (6) không có tiền sử chiếu xạ vùng cổ; (7) không có tiền sử ung thư tuyến giáp có tính chất gia đình.

\section{TÀI LIÊU THAM KHẢO}

1. Donatini G, Castagnet $M$, Desurmont $T$, Rudolph N, Othman D, Kraimps JL. Partial Thyroidectomy for Papillary Thyroid Microcarcinoma: Is Completion Total Thyroidectomy Indicated? World J Surg. 2016; 40(3):510-515. doi:10.1007/s00268-015-3327-7

2. Partial thyroidectomy for papillary thyroid microcarcinoma: Is completion total thyroidectomy indicated? - ScienceDirect. Accessed August 17, 2021. https://www.sciencedirect.com/ science/ article/pii/S1743919117301358?via\%3Dihub

3. Kim SK, Park I, Woo J-W, et al. Total thyroidectomy versus lobectomy in conventional papillary thyroid microcarcinoma: Analysis of 8,676 patients at a single institution. Surgery. 2017;161(2):485-492.

doi:10.1016/j.surg.2016.07.037

4. Jeon YW, Gwak HG, Lim ST, Schneider J, Suh YJ. Long-Term Prognosis of Unilateral and Multifocal Papillary Thyroid Microcarcinoma After Unilateral Lobectomy Versus Total Thyroidectomy. Ann Surg Oncol. 2019;26(9):2952-2958. doi:10.1245/s10434-019-07482-w

5. Kwon H, Jeon MJ, Kim WG, et al. A comparison of lobectomy and total thyroidectomy in patients with papillary thyroid microcarcinoma: a retrospective individual risk factor-matched cohort study. Eur J Endocrinol. 2017;176(4):371-378. doi:10.1530/EJE-16-0845

6. Xue $S$, Wang $P$, Liu J, Chen G. Total thyroidectomy may be more reasonable as initial surgery in unilateral multifocal papillary thyroid microcarcinoma: a single-center experience. World J Surg Oncol. 2017;15(1):62. doi:10.1186/s12957017-1130-7

7. Choi YS, Kim DW, Lee YJ, Ha TK, Jung SJ, Baek HJ. Appropriate Neck Ultrasonography Surveillance During the First 10 Years After Hemithyroidectomy in Papillary Thyroid Microcarcinoma Patients: A Single-Center Study. Ultrasound Q. 2019;35(3):275-280. doi:10.1097/RUQ.0000000000000429

8. Baek HJ, Kim DW, Lee CY, Huh JY, Sung JY, 
Choi Yj. ANALYSIS OF POSTOPERATIVE ULTRASONOGRAPHY SURVEILLANCE AFTER HEMITHYROIDECTOMY IN PATIENTS WITH PAPILLARY THYROID MICROCARCINOMA: A MULTICENTER STUDY. Endocr Pract Off J Am Coll Endocrinol Am Assoc Clin Endocrinol.
2017;23(7):794-802. doi:10.4158/EP161723.OR

9. Kim DW. Long-term follow-up ultrasonography after lobectomy in papillary thyroid microcarcinoma patients: A single-center study. Endocr Res. 2016:41(3):213-217.

doi:10.3109/07435800.2015.1137583

\section{TÌM HIỂU VAI TRÒ CỦA CA 125, HE4 VÀ ROMA TEST TRONG DƯ ĐOÁN UNG THƯ BUỒNG TRỨNG TẠI BÊ̂NH VIỆN PHỤ SẢN HÀ NộI}

\section{Phan Đức Long ${ }^{1}$, Lê Thị Anh Đào ${ }^{2}$, Trương Quang Vinh ${ }^{3}$}

\section{TÓM TẮT}

Chẩn đoán ung thư buồng trứng sớm thường rất khó khăn do các dấu hiệu lậm sàng mờ nhat, biên pháp chẩn đoán hình ảnh phu thuộc rất nhiều vào kinh nghiệm và kỹ năng của người đọc. Các xét nghiêm $\mathrm{CA} 125$ và $\mathrm{HE} 4$ và ROMA test đã được chứng minh có khả năng dự đoán nguy cơ ung thư của khối u buồng trứng. Nghiên cứu nhằm mục tiêu: Xác định giá trị dự đoán của CA125, HE4 và ROMA test trong ung thư buồng trứng tại quần thể bệnh nhân u buồng trứng được phẫu thuật tại bệnh viện Phụ Sản Hà Nối năm 2018-2019. Nghiên cứu mô tả cắt ngang, tiến cứu từ 8/2018 đến tháng 6/2019. Các bệnh nhân có u buồng trứng xét nghiệm CA 125 HE4 và ROMA test trước mổ sau đó được phẫu thuật tại bệnh viện Phu Sản Hà Nội. Dưa theo kết quả giải phấu bệnh lý sau mổ để đánh giá độ nhậy, độ đặc hiệu của 3 xét nghiệm này. Kết quả: Trong 209 bệnh nhân u buồng trứng, có 33 bệnh nhân ung thư buồng trứng. Độ nhậy và độ đặc hiệu của CA125 trong ung thư biểu mô buồng trứng (UTBMBT) là $88 \%, 70 \%$. Độ nhạy và độ đặc hiệu của HE4 trong UTBMBT là $64 \%$ và $96.6 \%$. Độ nhạy và độ đặc hiệu của ROMA test trong UTBMBT là $92 \%$, độ đẳc hiệu ROMA $=55.32 \%$. Kết luân: $C A$ 125 và HE4 riêng lẻ đều có giá trị dự đoán UTBMBT, nên phối hợp CA 125 và HE4 trong dự đoán UTBMBT.

Tư khóa: CA 125, HE4, ROMA test, ung thư biểu mô buồng trứng

\section{SUMMARY CA125, HE4 AND ROMA TESTS IN \\ ${ }^{1}$ Bệnh viện Đa Khoa Nông Nghiệp \\ ${ }^{2}$ Dại học Y Hà Nọi \\ ${ }^{3}$ Trường Đại học Y Dược, ĐHQG Hà Nọi \\ Chịu trách nhiệm chính: Lê Thị Anh Đào \\ Email: leanhdao1610@gmail.com \\ Ngày nhân bài: 22.10.2021 \\ Ngày phản biên khoa họ: 17.12.2021 \\ Ngày duyệt bài: 27.12.2021}

DETERMINE THE PREDICTED VALUE OF DIAGNOSE OVARIAN CANCER AT HANOI OBSTETRICS AND GYNECOLOGY HOSPITAL

Diagnosis of ovarian cancer is often late and difficult, due to the lack of specific signs. Ultrasounds or IRM images can not diagnose ovarian cancer as well. CA 125 and HE 4 tests and ROMA tests have been shown to predict ovarian cancer risk. The study aims to: Determine the predicted value of CA125, HE4 and ROMA tests in diagnose ovarian cancer in the population of ovarian tumor patients undergoing surgery at Hanoi Obstetrics and Gynecology hospital in 2018-2019. This is a cross sectional study has implemented from August 2018 to June 2019. Patients with ovarian tumors have been tested CA 125, HE4 and ROMA test before surgery. Based on the pathology's results after surgery to assess the sensitivity and specificity of these 3 tests. Results: Of the 209 patients with ovarian cancer, 33 had ovarian cancer. The sensitivity and specificity of CA125 in ovarian carcinoma are $88 \%, 70 \%$. The sensitivity and specificity of HE4 in UTBMBT are $64 \%$ and $96.6 \%$. The sensitivity and specificity of ROMA test in UTBMBT are $92 \%$, specificity ROMA $=55.32 \%$. Conclusions: CA 125 and HE4 have predictive values in diagnosing ovarian cancer, the combination between CA 125 and HE4 is better than single test.

\section{I. ĐĂT VẤN ĐỀ}

Ung thư buông trứng (UTBT) là loại ung thư ác tính nhất trong các ung thư phụ khoa, có tỷ lệ đứng thứ 3 sau ung thư cổ tử cung và ung thư vú ở phụ nữ, chiếm khoảng $5 \%$ trong các bệnh ung thư ở nữ giới [1]. Ở Việt Nam, tỷ lệ này là khoảng 3 đến 4.5/100.000 phụ nữ mỗi năm [2].

Tỷ lệ tử vong của UTBT cao và tỷ lệ sống sót tương đối trên 5 năm chưa đến $40 \%$ do bệnh thường chỉ được phát hiện ở giai đoạn muộn, chỉ khoảng 15\% số trường hợp được phát hiện sớm mà thôi [3]. Để chẩn đoán sớm UTBT thường phải kết hợp lâm sàng với các phương pháp chẩn đoán hình ảnh và xét nghiệm chất chỉ điểm $u$. Tuy nhiên, các triệu chứng lâm sàng trong giai đoan sớm của bệnh thường nghèo nàn. Các hình ảnh siêu âm để phát hiện ung thư buồng trứng cũng tương đối phong phú và đòi hỏi kinh nghiệm của người làm siêu âm. Do đó, việc dự đoán ung thư buồng trứng trước mố dựa rất nhiều vào xét nghiệm chất chỉ điểm u. Hiện nay, chất chỉ điểm u thường được dùng để dự đoán ung thư buồng trứng trên thế giới là CA125 (cancer antigen 125 ) và HE4 (human epididymal 